\title{
Spatio-temporal evolution characteristics of precipitation in the north and south of Qin-ba Mountain area in recent 43 years
}

\author{
Zhigang Cheng ${ }^{1,2,3}$ (D) Xiaoxiao Chen ${ }^{1,2} \cdot$ Yueyue Zhang ${ }^{1,2} \cdot$ Liya Jin $^{1,2}$
}

Received: 12 September 2019 / Accepted: 13 August 2020 / Published online: 25 August 2020

(C) The Author(s) 2020

\begin{abstract}
Using the daily precipitation data at 89 stations during 1975-2017 in the Qin-ba Mountain area, variation characteristics of different-grade precipitation in the north and south of the Qin-ba Mountain area are analyzed by the linear regression, Mann-Kendall test, and correlation analysis, based on the precipitation grade classification standard proposed by Dai Aiguo and the division of the geo-ecological boundary in mountain range presented by Kang Muyi. The results are as follows: (1) Light rain occurs most frequently, and the percentage of light rain in the north is twice that of the southern region. Rainstorms are the most rare. Precipitation above $800 \mathrm{~mm}$ mainly occurs south of the study area, and the result is consistent with the boundary between the north and south of the precipitation. (2) The beginning of precipitation mainly occurs in early April. The high precipitation concentration (PCD) in the north is an important reason for the debris flow disaster. The north-south precipitation concentration period (PCP) is about 1 month ahead of the central part. (3) In the past 43 years, the overall precipitation in the Qin-ba Mountain area has shown a decreasing trend, with the frequency of light rain and the percentage of heavy rain decreasing year by year. (4) The frequency of light rain is negatively correlated with other frequencies. In addition, the fewer days of precipitation, the later the precipitation concentration period (PCP) occurs, which means that the disaster occurs later.
\end{abstract}

Keywords Qin-ba Mountain area $\cdot$ Precipitation grades $\cdot$ Precipitation concentration degree $\cdot$ Precipitation concentration period

\section{Introduction}

In recent years, the global climate has changed significantly. Precipitation is one of the most sensitive meteorological factors in response to the global change, and its frequency and intensity are closely related to

Responsible Editor: Zhihua Zhang

Zhigang Cheng

chengzg@ @uit.edu.cn

1 School of Atmospheric Sciences, Chengdu University of Science and Technology, Chengdu, China

2 Plateau Atmoshphere and Environment Key Laboratory of Sichuan Province, Chengdu University of Science and Technology, Chengdu, China

3 College of Atmoshperic Science, Chengdu University of Information and Technology, No.24 Block 1, Xuefu Road, Chengdu 610225, China meteorological disasters such as rainstorm, flood, and drought (Yin and Sun 2007; Xie et al. 2018). Previous studies show that extreme precipitation events are significantly different in different regions. Except for North China and Sichuan Basin, extreme precipitation events increase obviously in China (Zhai et al. 2005). Furthermore, the heavy rain and rainstorm days in the middle and lower reaches of the Yangtze River increase significantly ( $\mathrm{Fu}$ et al. 2008; Zhang et al. 2007). The light rain days in East China is the greatest contributor to the total precipitation days (Wu et al. 2013; Ai et al. 2009), and the rainstorm contributes the most to the total summer rainfall. The frequency of light rain shows a significant negative correlation with the frequencies of the others (Bai et al. 2014). In the north of East China, the precipitation concentration degree (PCD) is significantly higher than that in the south and the precipitation concentration period (PCP) is significantly postponed (Bai and Liu 2010). 


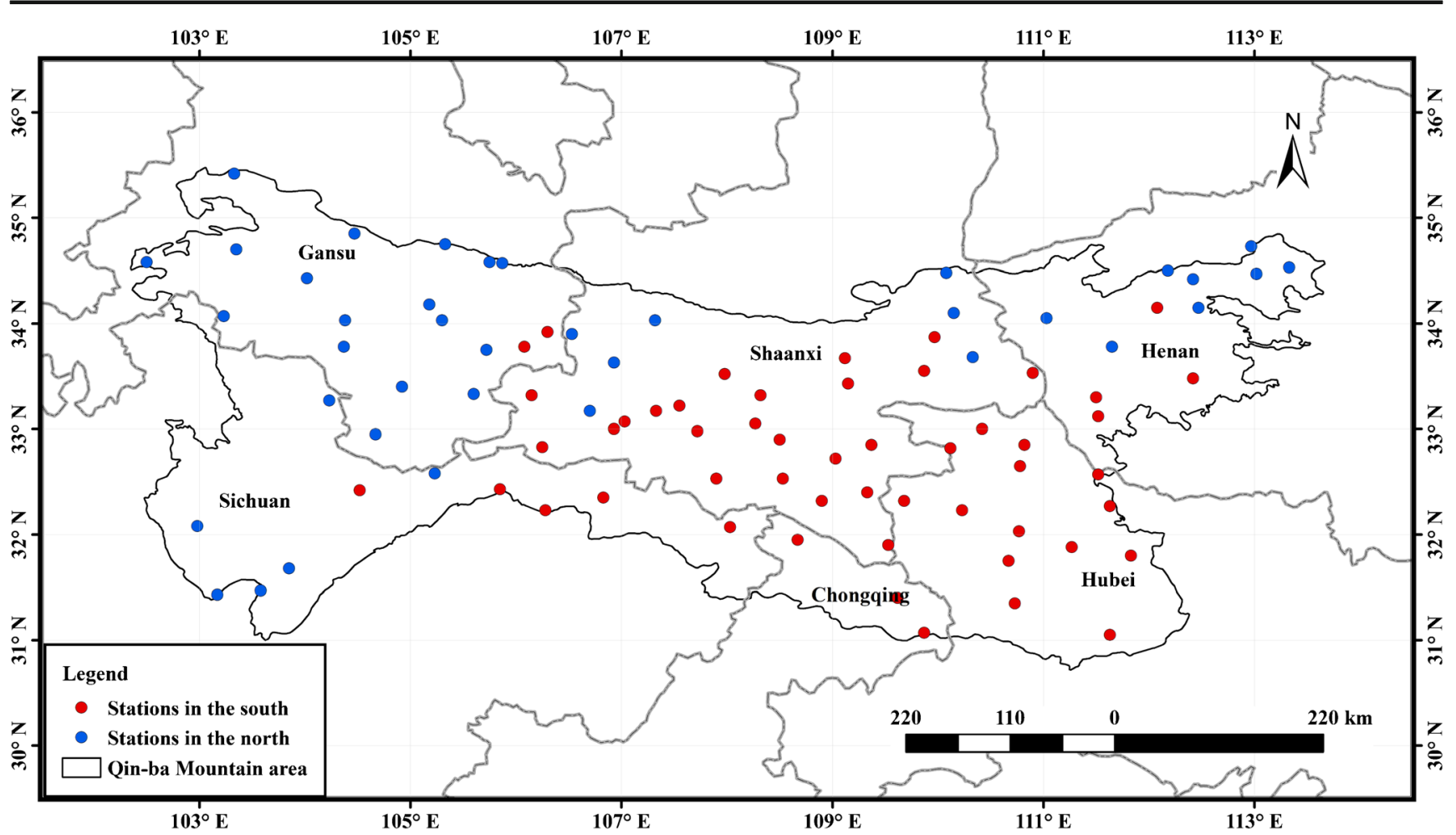

Fig. 1 Distributions of 89 stations in the north and south of the Qin-ba Mountain area (north, blue; south, red)

The Qin-ba Mountain area is located in China's transitional climate zone between north and south. It crosses six provinces namely Gansu, Sichuan, Shaanxi, Chongqing, Henan, and Hubei and belongs to the East Asian monsoon region. As a traditional rain-fed agriculture area and one of the regions that most influenced by extreme precipitation events at the same latitude (Yang et al. 2014), it is of great importance to reveal the variation characteristics of precipitation in this area. Previous studies in this area mainly focused on the variations of precipitation amount at different spatial and temporal scales (Gao et al. 2012; Jiang et al. 2012; Zhu et al. 2014; Liu et al. 2008) or the characteristic analysis of extreme precipitation events ( $\mathrm{Li}$ et al. 2015). Besides, due to the limited research areas and stations (Wang et al. 2016; Chen et al. 2019; Wang and Ren 2012), the representativeness and coverage of previous studies are insufficient. Therefore, by using daily precipitation data at 97 stations in the Qin-ba Mountain area, this paper conducts in-depth analyses of precipitation days, precipitation frequency, PCD, and PCP in the northern and southern areas for different precipitation grades, providing references for the integrated management of water resources and disaster prevention and mitigation in this area. Gansu Bailong River Basin, and other areas in China, is one of landslide hazards, and the most serious are located in the study area west Qinling Mountains, at the same time across the entire study area in the middle reaches of the Yangtze River; research is not only on different levels of precipitation in the Qinba Mountain landslide in the area. This study of geological hazards is of guiding significance and has early warning significance for the precipitation time and flood disasters in the middle and lower reaches of the Yangtze River.

\section{Data and methods}

\section{Research area}

Qin refers to the Qinling Mountains, and Ba refers to the Daba Mountains. The Qin-ba mountainous area refers to the Qinling Daba Mountain and its adjacent area, the largest tributary of

Table 1 The precipitation angle range and central angle of each month (unit: degree)

\begin{tabular}{|c|c|c|c|c|c|c|c|c|c|c|c|c|c|c|c|c|c|c|c|c|c|c|c|c|}
\hline Month & 1 & & 2 & & 3 & & 4 & & 5 & & 6 & & 7 & & 8 & & 9 & & 10 & & 11 & & 12 & \\
\hline Angle range & & 15 & & 45 & & 75 & & 105 & & 135 & & 165 & & 195 & & 225 & & 255 & & 285 & & 315 & & 345 \\
\hline Angle central & 0 & & 30 & & 60 & & 90 & & 120 & & 150 & & 180 & & 210 & & 240 & & 270 & & 300 & & 330 & \\
\hline
\end{tabular}




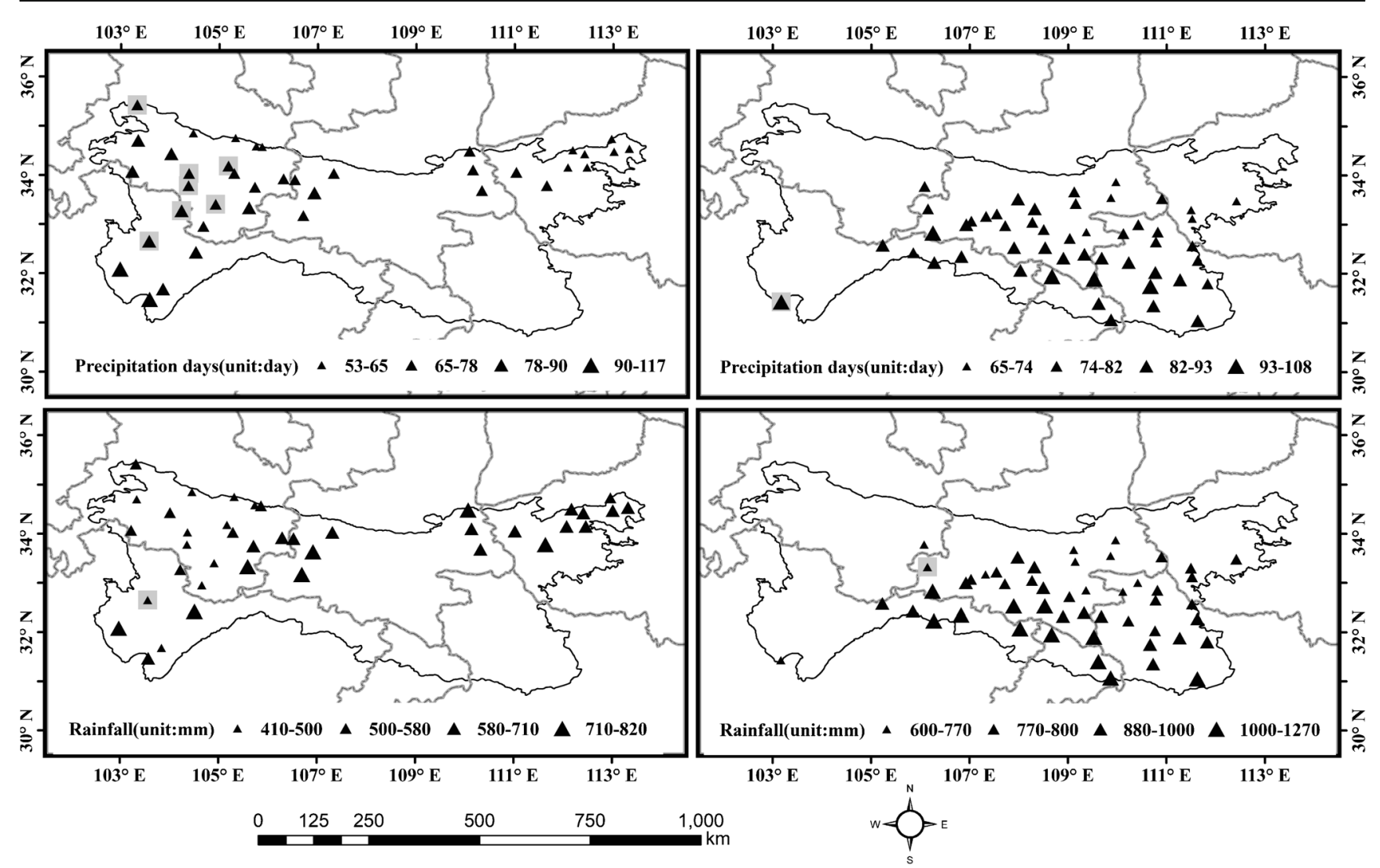

Fig. 2 Spatial distributions of annual average precipitation days and rainfall in the northern and southern areas (the shaded area represents a $90 \%$ significance test)

the Yangtze River - the upper reaches of the Hanshui River. It spans six provinces and cities, namely Gansu, Sichuan, Shaanxi, Chongqing, Henan, and Hubei. There are many small basins connected with valleys between mountains, among which the Hanzhong Basin, Xixiang Basin, Ankang Basin, Hanyin Basin, Shangdan Basin, and Luonan Basin are the most famous. The Qin-ba Mountain area is also an important ecological barrier in the upper reaches of the Yangtze River, where water, heat, forests, grass resources, native products, and mineral resources are extremely rich. Because of the abundant production of Gynostemma pentaphyllum, it is known as "the world's skein valley."

\section{Data}

The data used in this paper is the daily precipitation data in recent 43 years (1975-2017) obtained from the National Meteorological Center, covering 89 stations in the Qin-ba Mountain area $\left(30^{\circ} \mathrm{N}-36^{\circ} \mathrm{N}, 102^{\circ} \mathrm{E}-114^{\circ} \mathrm{E}\right)$. Based on the missing value processing method proposed by Ning and Qian (2008), the data is processed. All of the relocated stations and stations with missing values over $5 \%$ in any year are excluded, and the remaining missing values are interpolated by the observations before and after at the same station or adjacent stations. Thus, 89 stations with complete data are selected for analysis. According to the geo-ecological boundary in Qinling Mountain Range based on the distribution of climate-vegetation contours proposed by Kang and Zhu (2006), the temporal and spatial distribution characteristics of precipitation in the north and south of the Qin-ba Mountain area are analyzed (Fig. 1).

\section{Methods}

This article uses the FORTRAN language to process data. The drawing software mainly uses ArcGIS 10.3 version, combined with traditional spatial analysis, synthetic analysis, and linear analysis methods. The daily precipitation standard defined by Dai et al. (2007) is adopted in this paper. $P$ represents the daily precipitation, with $1 \mathrm{~mm} /$ day as the critical value; the rainfall is classified as follows: no rain $(P<1 \mathrm{~mm})$, light rain $(1 \leq$ $P<10 \mathrm{~mm})$, medium rain $(10 \leq P<25 \mathrm{~mm})$, heavy rain $(25 \leq P<50 \mathrm{~mm})$, and rainstorm $(P \geq 50 \mathrm{~mm})$. 
$103^{\circ} \mathrm{E} \quad 105^{\circ} \mathrm{E} \quad 107^{\circ} \mathrm{E} \quad 109^{\circ} \mathrm{E} \quad 111^{\circ} \mathrm{E} \quad 113^{\circ} \mathrm{E}$
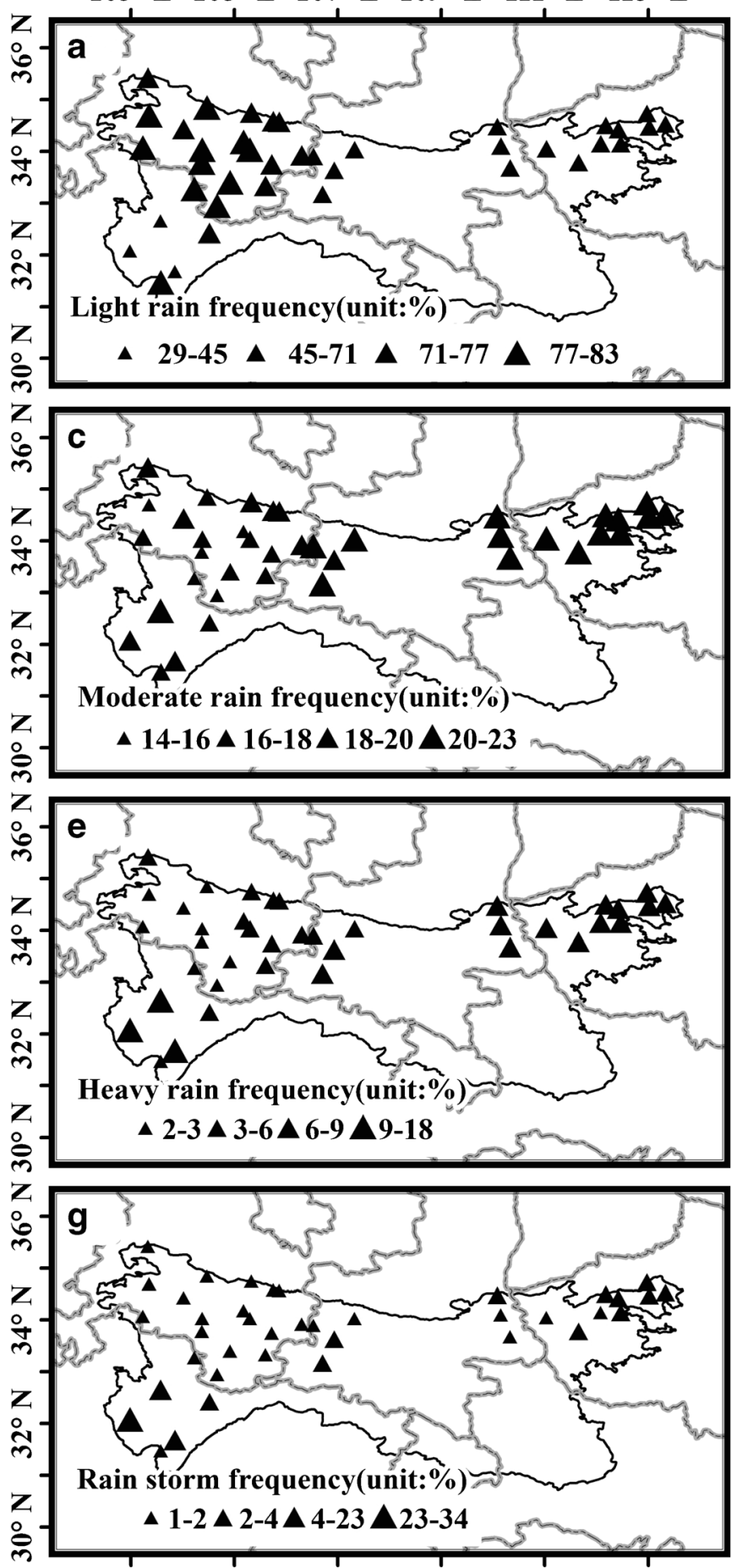

$103^{\circ} \mathrm{E} 105^{\circ} \mathrm{E} 107^{\circ} \mathrm{E} 109^{\circ} \mathrm{E} 111^{\circ} \mathrm{E} 113^{\circ} \mathrm{E}$ $103^{\circ} \mathrm{E} 105^{\circ} \mathrm{E} \quad 107^{\circ} \mathrm{E} \quad 109^{\circ} \mathrm{E} \quad 111^{\circ} \mathrm{E} \quad 113^{\circ} \mathrm{E}$
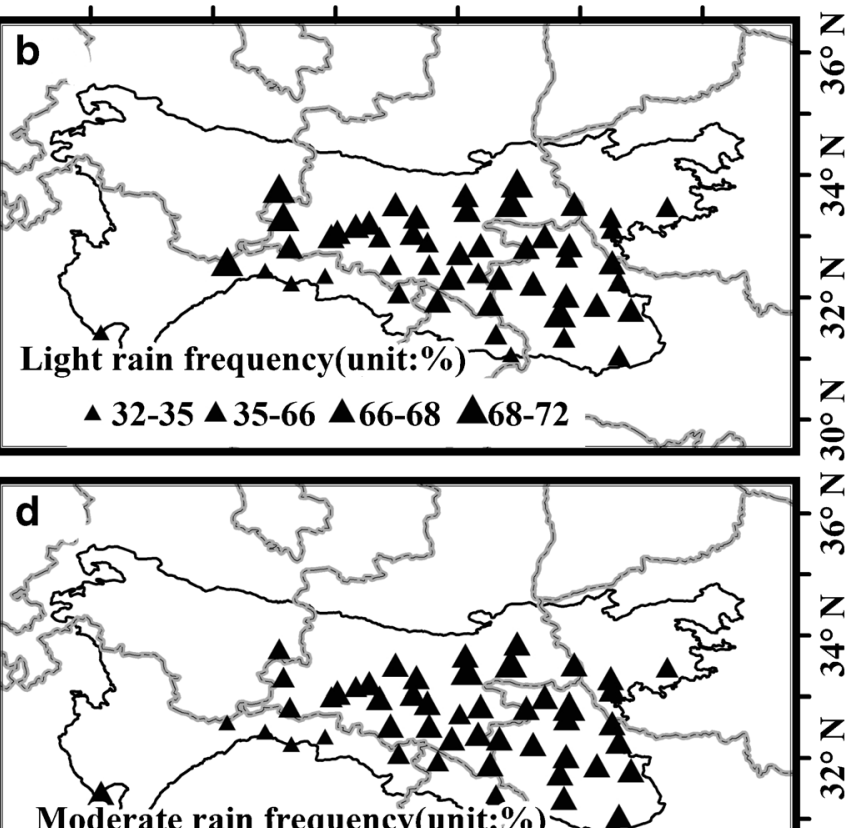

$\triangle 16-18 \triangle 18-20 \triangle 20-22 \triangle 22-23$
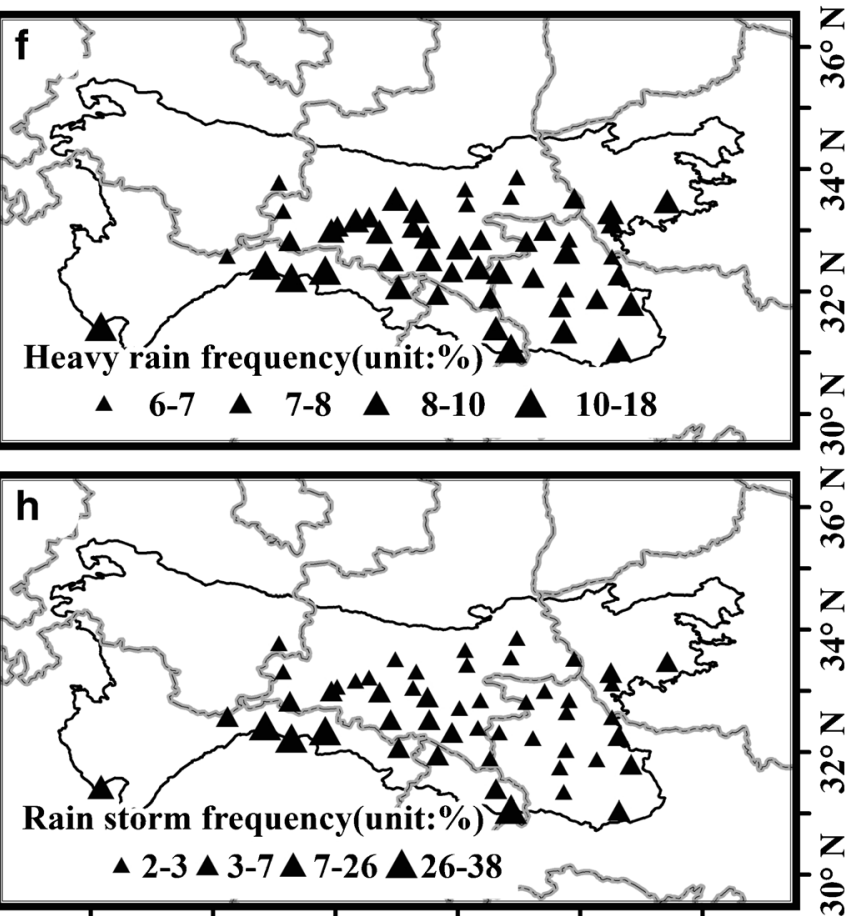

$103^{\circ} \mathrm{E} 105^{\circ} \mathrm{E} 107^{\circ} \mathrm{E} 109^{\circ} \mathrm{E} 111^{\circ} \mathrm{E} 113^{\circ} \mathrm{E}$

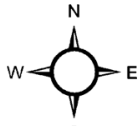

Fig. 3 Spatial distributions of annual average precipitation frequencies for different grades. Light rain $(\mathbf{a}, \mathbf{b})$; moderate rain $(\mathbf{c}, \mathbf{d})$; heavy rain $(\mathbf{e}, \mathbf{f})$; rainstorm (g, h) (unit: \%)

The method proposed by Bai et al. (2014) is adopted for the frequency and percentage of each-grade rainfall. $N$ represents annual total precipitation days, and the frequency of eachgrade precipitation can be described as follows. 
$f_{x}={ }^{N} / N$.

The percentage of each-grade precipitation is calculated as follows.

$r_{x}={ }^{P_{x}} / P$

where $X$ represents the subscript of each-grade precipitation and the sum of percentages for all the precipitation grades is 1 .

Based on the method of the PCD and PCP proposed by Zhang and Qian 2004 the amount of rainfall in each month is divided into horizontal and vertical directions, and the former and latter are expressed as the sine-value and cosine-value along the angle of each month, respectively. They can be expressed as follows.

$R_{x}=\sum_{i=1}^{12} r_{x i}=\sum_{i=1}^{12} r_{x i} \sin \theta_{i}$,

$R_{y}=\sum_{i=1}^{12} r_{y i}=\sum_{i=1}^{12} r_{y i} \cos \theta_{i}$,

$R=\sqrt{\left(R_{x} 2+R_{y}^{\wedge}\right)}$,

$\omega=\sum_{i=1}^{12} r_{i}$

And the PCD $\left(\mathrm{C}_{\mathrm{n}}\right)$ is defined as follows.

$C_{n}={ }^{R} / \omega$

The PCP (D) is defined as follows.

$D=\arctan \left(R_{x} / R_{y}\right)$

The angle of each month is defined in Table 1.

\section{Spatial distributions of precipitation variations in different grades}

\section{Spatial distributions of the annual average total precipitation days and rainfall}

It can be seen that the precipitation mainly occurs in the southern area. The difference in annual average precipitation days between the southern and northern areas is little, but the annual average precipitation days in the southern area are all above 65 days and slightly more than those of the north area. Yet the maximal and minimal precipitation days are both found in the northern area, with a maximum of 117 days observed in Sichuan Province and a minimum of 53 days observed in Henan Province in the northeastern area. However, only the data at a few stations in the western area pass the $90 \%$ significance test. The annual average rainfall in the southern area is significantly higher than that in the northern area. The annual average rainfall in the north is basically below $820 \mathrm{~mm}$ and that in the south is mainly concentrated in the central part of the research area, with a maximum up to $1270 \mathrm{~mm}$, which is consistent with the Huaihe River-Qinling Mountain boundary of 800-mm rainfall contour (Fig. 2).

\section{Spatial distributions of the different-grade precipita- tion's frequency and percentage}

In the northern and southern areas, for the different-grade rain, the light rain occurs the most frequently, followed by the moderate rain, and the heavy rain occurs less frequently than the moderate rain, while rainstorms are the most rare. The frequencies of light rain in both areas are above $30 \%$, despite the fact that the frequency in the north area is higher. In the northern area, the light rain and moderate rain occur more frequently in the west part and east part, respectively. It is worth noting that the frequency of moderate rain is up to one-fifth of the total precipitation frequency. Moreover, the frequencies of heavy rain and rainstorms in the northern area are less than those in the southern area, and the rainstorm generally occurs less frequently, which appears mainly in Sichuan Province and Chongqing Province, with a maximum frequency of $38 \%$ in the southern area (Fig. 3).

The percentages in decreasing order are percentages of rainstorm, moderate rain, heavy rain, and light rain. The percentage of rainstorm is the highest, with a maximum value of 90\% in Sichuan Province and Chongqing Province, which is consistent with its corresponding frequency. The percentage of light, moderate, and heavy rain in the north is higher than that in the south, but it is opposite for the rainstorm. The percentage of light rain in the northern area is as two times as that in the southern area. The comparatively larger percentage of light rain in the north is likely to be related to its frequency which is at maximum. The percentages of light rain (Fig. 4a and b) and moderate rain (Fig. 4c and d) both increase from south to north in the research area, and the average amount of the two-grade precipitation can reach one-quarter of the total precipitation. In short, in the northern area, the light rain and moderate rain concentrate in the west part and the heavy rain and rainstorms concentrate the in the east part. In the southern area, the rainstorm concentrates in the south part and the other-grade precipitations concentrate in the middle part.

\section{Spatial distributions of the PCD and PCD}

The analysis of the PCD and PCP shows that the annual average PCD in the research area is $54 \%$, and the PCD in the north which is basically above $50 \%$ is obviously higher than that in the south. The result indicates that the precipitation is more abundant and concentrated in 
$103^{\circ} \mathrm{E} \quad 105^{\circ} \mathrm{E} \quad 107^{\circ} \mathrm{E} \quad 109^{\circ} \mathrm{E} \quad 111^{\circ} \mathrm{E} \quad 113^{\circ} \mathrm{E}$
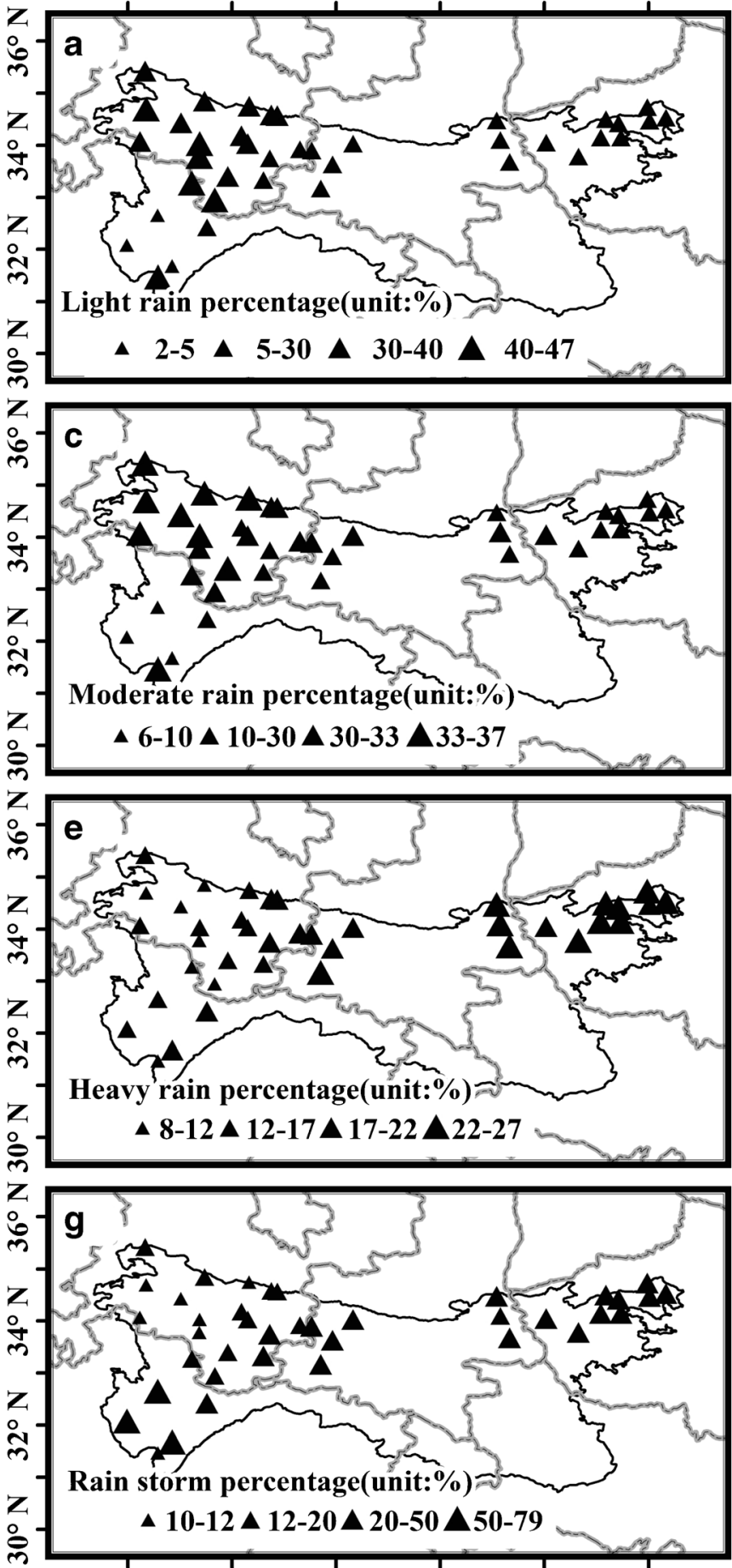

$103^{\circ} \mathrm{E} 105^{\circ} \mathrm{E} 107^{\circ} \mathrm{E} 109^{\circ} \mathrm{E} 111^{\circ} \mathrm{E} 113^{\circ} \mathrm{E}$ $103^{\circ} \mathrm{E} \quad 105^{\circ} \mathrm{F} \quad 107^{\circ} \mathrm{E} \quad 109^{\circ} \mathrm{F} \quad 111^{\circ} \mathrm{F} \quad 113^{\circ} \mathrm{E}$
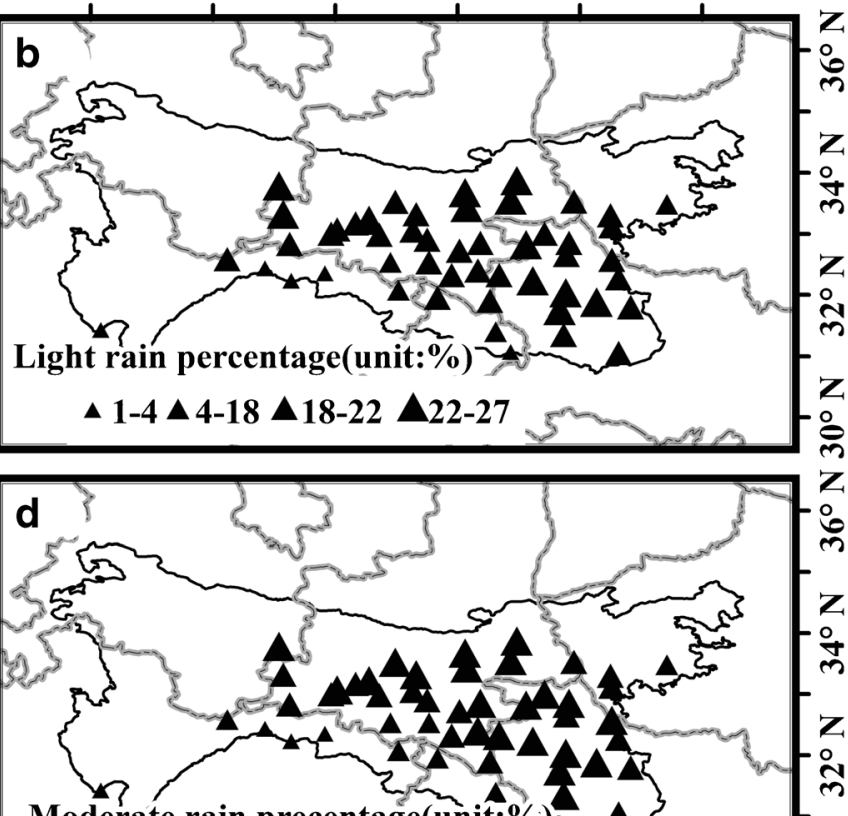

Moderate rain precentage(unit:\%)

$\Delta \quad 3-9 \Delta$ 9-23 $\triangle 23-27 \Delta$ 27-32

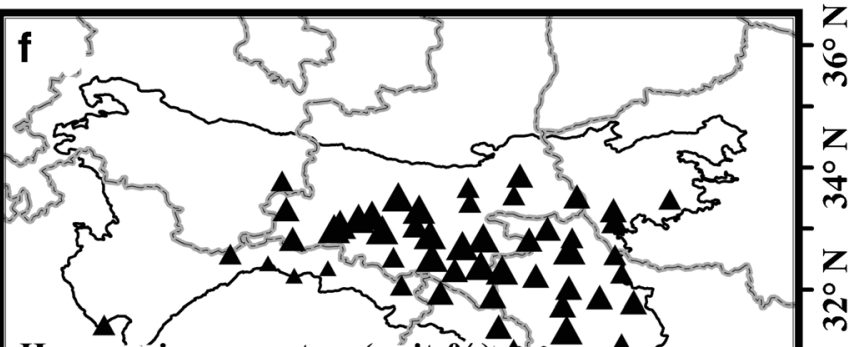

Heavy rain percentage (unit: $\%)$

$\triangle 5-6 \triangle 6-21 \Delta 21-23 \Delta 23-27$

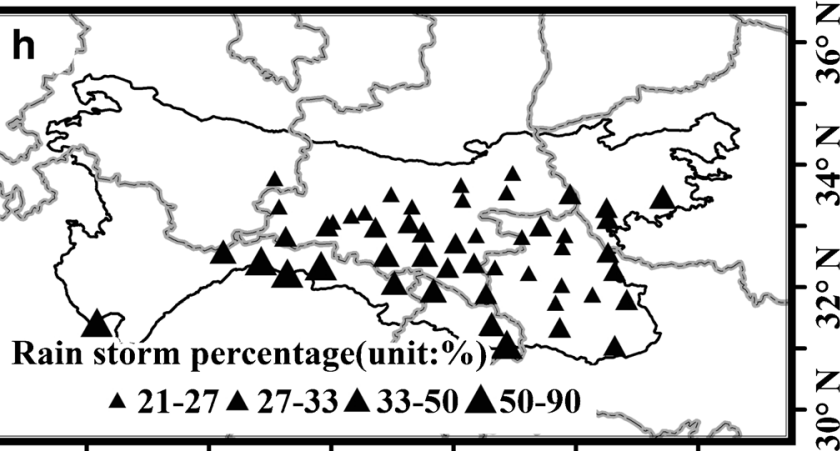

$103^{\circ} \mathrm{E} 105^{\circ} \mathrm{E} 107^{\circ} \mathrm{E} 109^{\circ} \mathrm{E} 111^{\circ} \mathrm{E} 113^{\circ} \mathrm{E}$

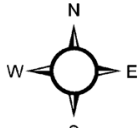

Fig. 4 Spatial distributions for annual percentages of differentgrade precipitation. Light rain (a, b); Moderate rain (c, d); Heavy rain (e, f); rainstorm (g, h)(unit:\%)

the north of the Qin-ba Mountain area, whereas the PCD in the south is lower, and the PCP is longer than that in the north and the temporal distribution of precipitation is more even. 
The annual average PCP in the Qin-ba Mountain area is 98 (Table 1), which indicates that the precipitation is mainly concentrated in early April, which is the PCP in the middle and lower reaches of the Yangtze River. The PCPs in the northwest of northern area and the southeast of the southern area in Qin-ba Mountains are about more than 1 month later than that in the middle area. The PCPs in the border between north and south, Chongqing Province and Hubei Province in the southern area, occur in early September. It corresponds to the autumn rain belt in West China and also reflects the north-south movement of precipitation during the rainy season in China (Fig. 5).

\section{Temporal distribution of the different-grade rainfall's variation}

\section{The variation of annual average precipitation days and rainfall}

In Fig. 6, the inter-annual variations of total precipitation days and rainfall in the northern and southern areas are basically the same. The annual average precipitation days and precipitation amount in the south are generally above
65 days and $500 \mathrm{~mm}$, respectively, and higher than those in the north. It is noticeable that the precipitation days and rainfall in this area exhibit a surge in 1983 and 2003. In the northern area, the precipitation days and rainfall reach their maximal values of 88 days and $780 \mathrm{~mm}$, respectively, in 2003. In the south, the precipitation days reach a maximum of 103 days in 1989 and the maximum rainfall is nearly $1300 \mathrm{~mm}$ in 1983 . Compared with previous studies (Yin et al. 2007; Duan and Tao 2004), it is found that severe droughts and floods occur in 1983, 2003, and 2011 when there are extreme values of precipitation, which is in good agreement with the analysis results in this paper.

\section{The variation of different-grade precipitation's fre- quency and percentage}

Figure 7 shows the frequencies of different-grade precipitation. It can be seen from the left figure that the order of different-grade precipitation from the most frequently to the least frequently is light rain, moderate rain, heavy rain, and rainstorm. The frequency of light rain is as high as over $65 \%$, and the others' are less than $30 \%$. The data reveals that the precipitation in this area is mainly dominated by the light rain, and the light rain days contribute the most to the total

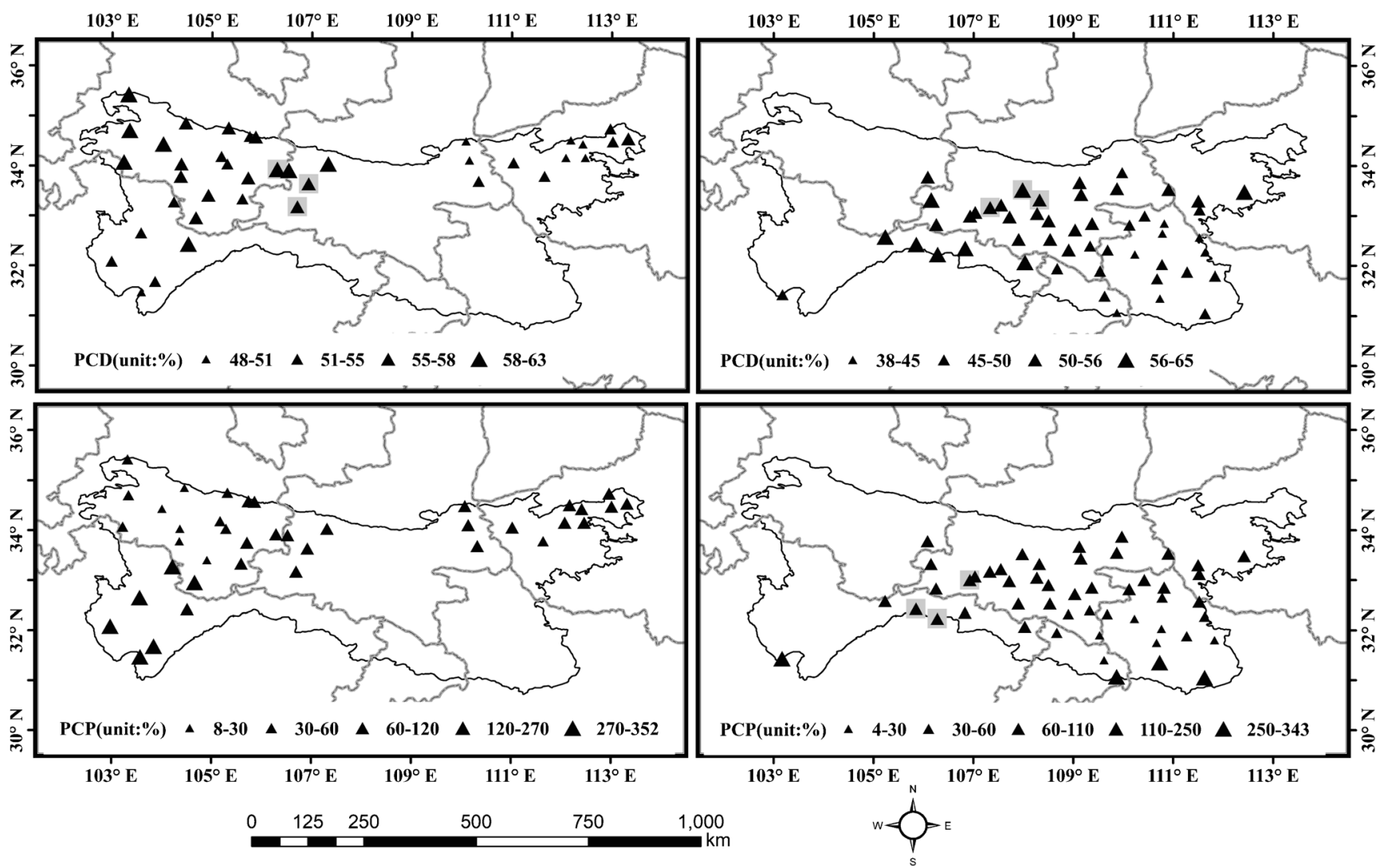

Fig. 5 Spatial distributions of annual average PCD and PCP in the northern and southern areas 
Fig. 6 The variation of annual average precipitation days and rainfall

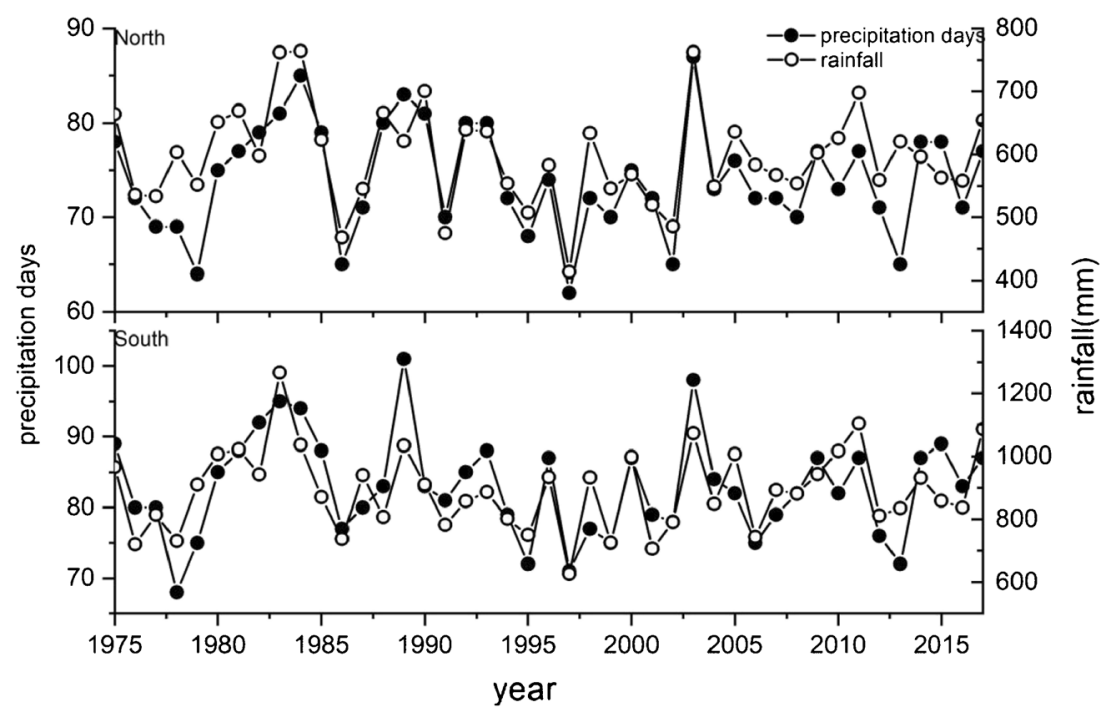

precipitation days. In the past 43 years, the frequencies of light rain and moderate rain have slightly decreased in the northern and southern areas, while slight increasing trends of heavy rain and rainstorm are observed. The frequency of light rain in the northern area is about $75 \%$, slightly higher than that in the southern area. Whereas the frequency of heavy rain in the south is significantly higher than that in the north, which illustrates that the extreme precipitation occurs mainly at the southern foot of the Qin-ba Mountain area.

Figure 8 shows the percentages of rainfall in different grades in the northern and southern areas and a significant difference between the two areas is noticed. The rainfall percentage of heavy rain is increasing year by year, yet the percentage of rainstorms is decreasing year by year. The rainfall percentage of moderate rain is relatively large with a value of over $30 \%$ and that of rainstorm is the least. Moreover, in the northern area, the rainfall percentages of light rain and moderate rain are increasing year by year and are significantly larger than that in the south, accounting for $35 \%$. While in the southern area, the percentages of heavy rain and rainstorm are significantly larger than those in the northern area. Severe droughts and floods happen more frequently in 1983, 2003, and 2011 when extreme values of rainstorm occur, indicating that the southern area is more prone to heavy rain processes. The rainstorm in the southern area contributes a large part to the total precipitation.
Fig. 7 The variation of precipitation frequencies in different grades in the northern and southern areas

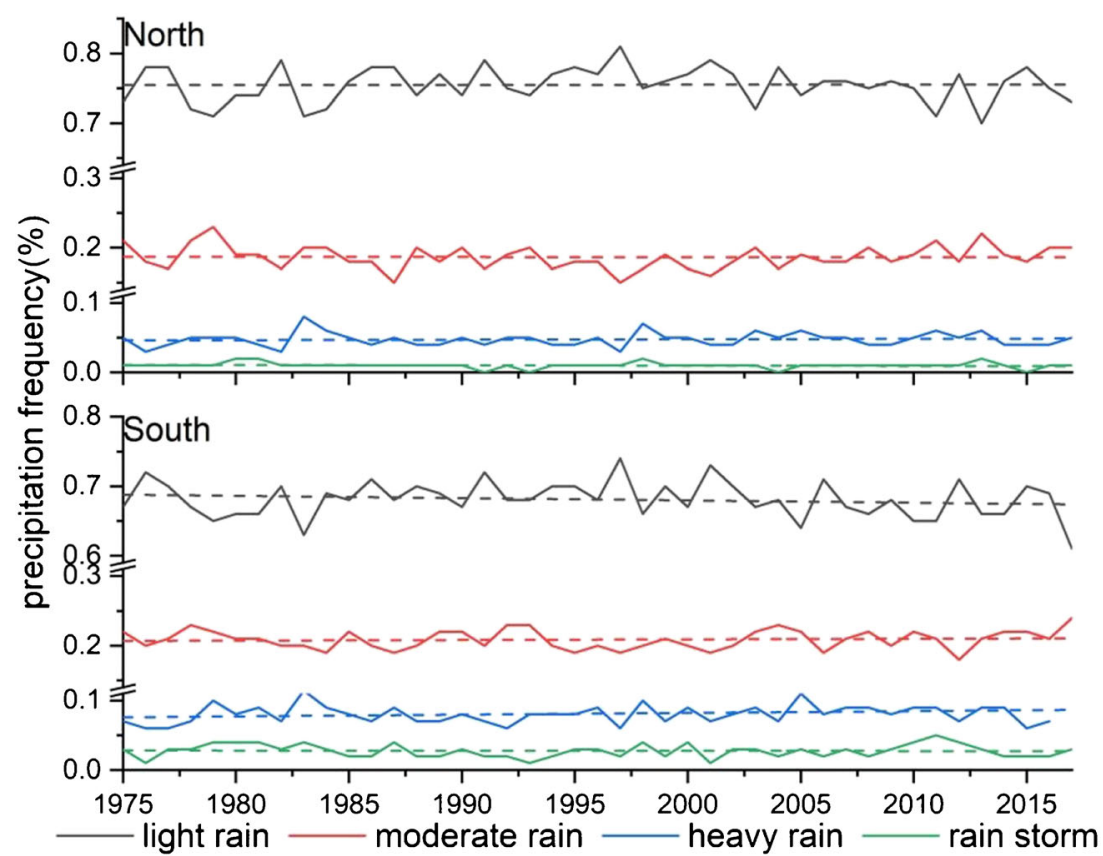


Fig. 8 Percentages of differentgrade rainfall in the northern and southern areas

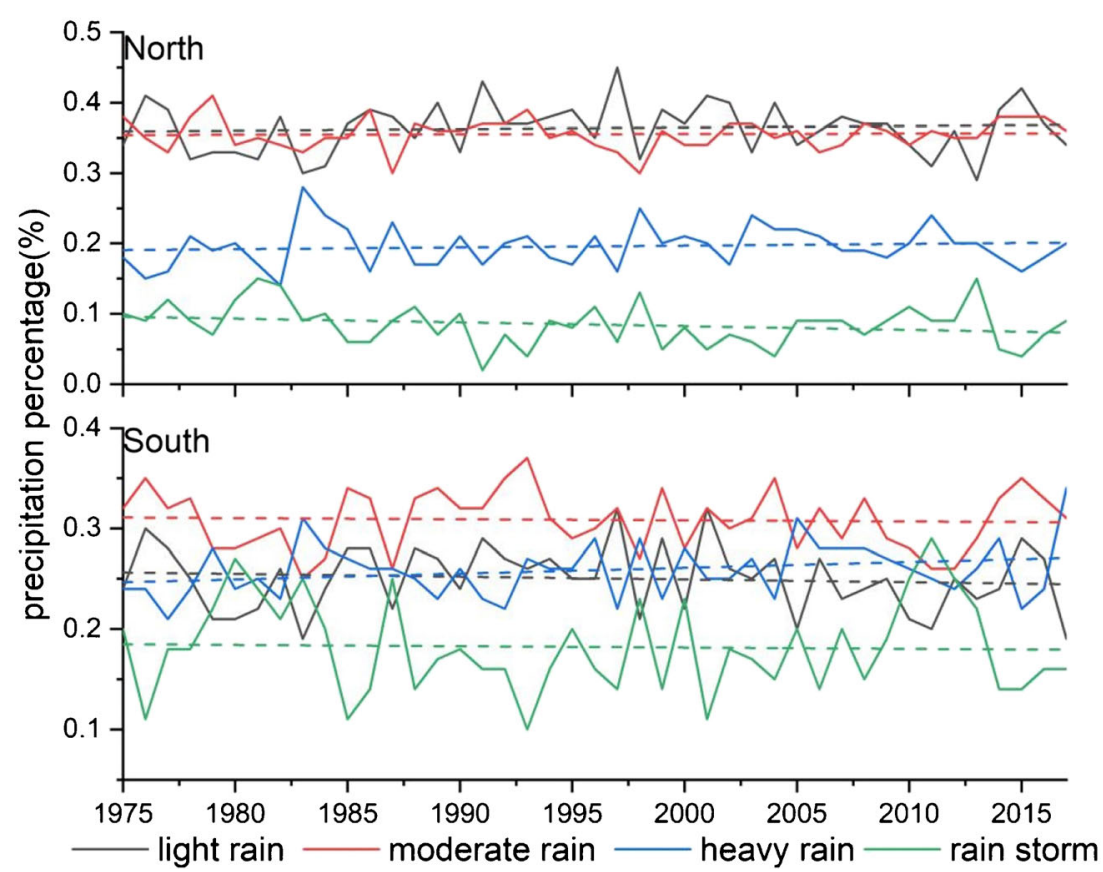

\section{Abrupt change analysis of precipitation days in different grades}

The total precipitation days and precipitation days in different grades are examined by the Mann-Kendall test for trend analysis and abrupt changes (Fig. 9). The number of precipitation days in different grades increases at first and then decreases, and two or more abrupt changes are found in all the grades (pass the 95\% significance test). As can be seen from Fig. 9a, the total precipitation days increase significantly during 1978 1985 and decrease significantly in the late 1990s. The abrupt change is first found in 1980 when the decreasing trend changes into a significant increasing trend. Another abrupt change is in 1990 when a significant decrease trend is observed.

Figure 9b-e shows that the abrupt change of precipitation days in different grades is around 1979, and it shifts from a decreasing trend to an increasing trend. The number of light rain days increases at first and then decreases. As for the moderate rain, heavy rain, and rainstorm, the rainy days increase initially and then decrease before another increasing trend. The peak shows up around 1985.

\section{The frequency of each-grade precipitation and its relationship with the rainfall variation}

We define that the summation of all frequencies for fourgrade precipitation is 1 . Thereby, if the frequency of anygrade precipitation increases, then the precipitation frequency for another different grade decreases. The correlation coefficients between precipitation frequencies in different grades are shown in Table 2. The precipitation frequency of light rain is negatively correlated with those of others, and its correlations with the frequencies of rainstorm and heavy rain are as high as -0.93 and 0.77 respectively. While the frequencies of heavy rain and rainstorm are positively correlated, their correlation coefficient up to 0.61. All the correlation coefficients have passed the $99 \%$ significance tests. This result could be due to the fact that most heavy rains tend to evolve into rainstorms. Nevertheless, this evolution needs further analysis in the future. The correlation between moderate and heavy rain frequencies is comparatively weak, indicating strong randomness between them.

Furthermore, a significant positive correlation is found between the precipitation frequency and the corresponding rainfall for different grades. The ascending order of correlation coefficient for different-grade precipitation is rainstorm, heavy rain, moderate rain, and light rain. The correlation between the precipitation frequency and rainfall of rainstorm is up to 0.99 , which indicates that the variation of rainstorm frequency can basically reflect the precipitation amount. As for heavy and moderate rain, the corresponding correlation coefficients are 0.86 and 0.47 , respectively, and pass the $99 \%$ significance test. Although the frequency of light rain is the highest, it has the weakest correlation with its precipitation amount (0.19), failing to pass the significance test.

Table 3 illustrates the correlations of precipitation with PCD and PCP, and both of them pass the $99 \%$ significance test. Except for the positive correlation between the 
Fig. 9 Mann-Kendall test of annual average precipitation days in different grades: total rain days (a); light rain days (b); moderate rain days $(\mathbf{c})$; heavy rain days $(\mathbf{d})$; rainstorm days (e)
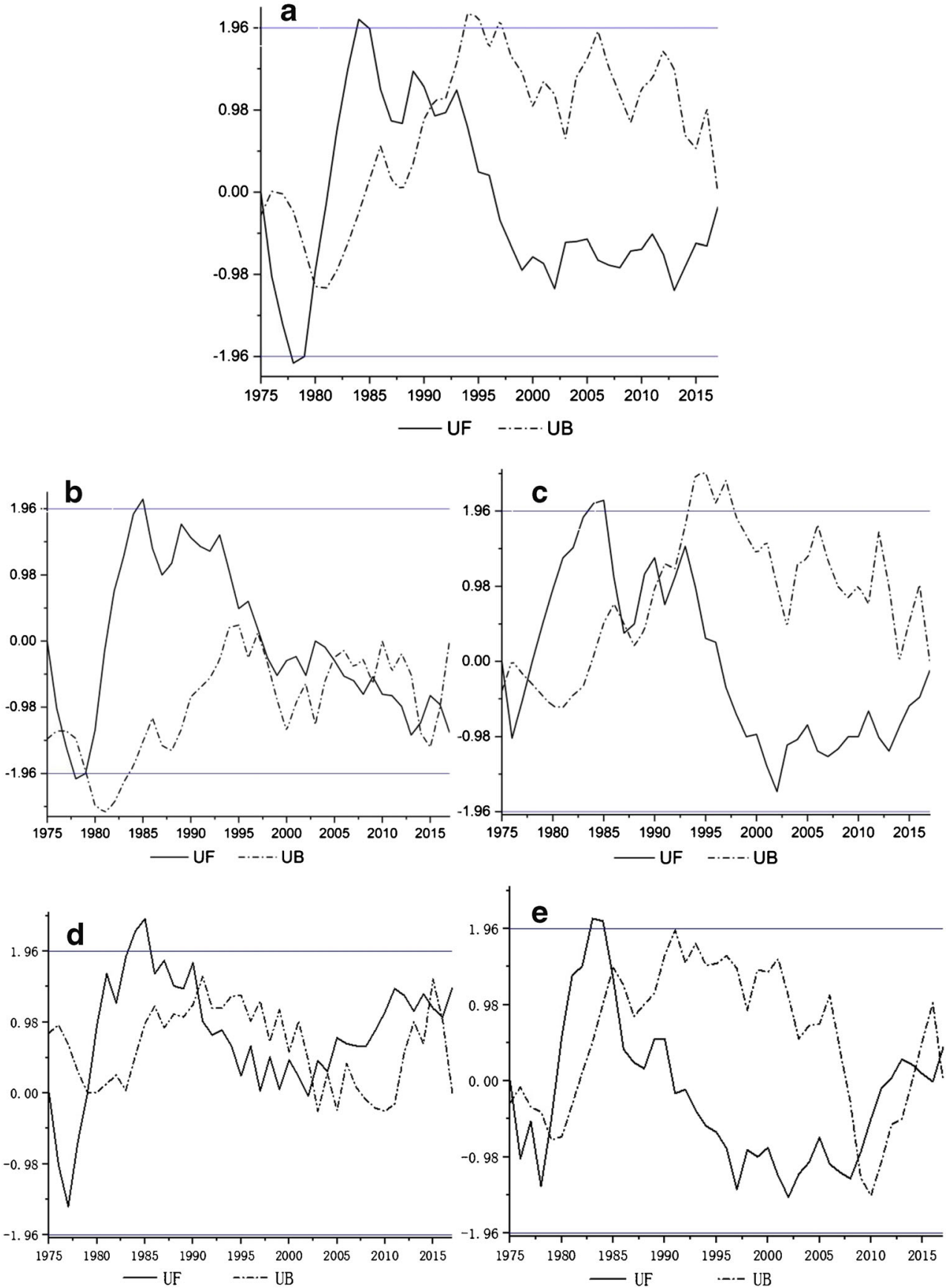

precipitation and the PCP, the others are negatively correlated. The correlation between precipitation days and the PCP is the most significantly negative, up to - 0.6. To sum up, the more precipitation days are, the more uneven the distribution of PCP will be, and the earlier the PCP will occur. The more precipitation there is, the more concentrated the PCP will be. In the year with high PCD, the rainfall and precipitation days are less, and the rainfalls occur in a certain area concentratedly.
Table 2 Correlation coefficients between precipitation frequencies in different grades (*represents passing the $99 \%$ significance test)

Light rain Moderate rain Heavy rain Rainstorm

\begin{tabular}{cllll}
\hline Light rain & 1 & & & \\
Moderate rain & -0.06 & 1 & & \\
Heavy rain & $-0.77^{*}$ & 0.04 & 1 & \\
Rain storm & $-0.93^{*}$ & -0.24 & $0.61^{*}$ & 1 \\
\hline
\end{tabular}


Table 3 Correlation coefficients of rainfall with the PCD and the PCP (*represents passing the $99 \%$ significance test)

\begin{tabular}{lll}
\hline & Precipitation & Precipitation day \\
\hline PCD & $-0.29^{*}$ & $-0.29^{*}$ \\
PCP & $0.33^{*}$ & $-0.6^{*}$ \\
\hline
\end{tabular}

\section{Conclusions and prospects}

Based on the daily precipitation data at 89 stations in the Qinba Mountain area, combined with the analysis of precipitation days, PCP, and PCD, the conclusions are drawn as follows:

1. The precipitation mainly occurs in the southern area of the Qin-ba Mountain area. The descending order of precipitation frequency is light rain, moderate rain, heavy rain, and rainstorm. The high frequencies of heavy rain and rainstorm are found mainly in the southern area. Moreover, the percentage of each-grade rainfall shows a reverse order with that of precipitation frequency. And the percentage of light rain in the north is as twice as that in the south.

2. The precipitation in the Qin-ba Mountain area is comparatively concentrated, and the PCD in the north is significantly higher than that in the south. The PCP mainly occurs in early April, but the PCPs in the northern and southern areas are about 1 month later than that in the middle area.

3. The light rain days contributes the most to the total precipitation days in this area. The frequencies of light rain and moderate rain show a decreasing trend. The frequency of heavy rain in the south is significantly higher than that in the north. The percentages of heavy rain in the northern and southern areas show an increasing trend year by year, whereas that of the rainstorm shows a decreasing trend year by year. The abrupt change first appears around 1980.

4. The precipitation frequency of light rain is negatively correlated with that of the rest. There is a significant positive correlation between the precipitation frequency and its corresponding rainfall in each grade. The higher the $\mathrm{PCD}$ is, the less the precipitation amount and precipitation days will be; the later the PCP is, the more the rainfall and the less the number of precipitation days will be.

Funding information This research was jointly supported by the Special Program for Basic Resources Survey of the Ministry of Science and Technology, China (2017FY00903), National Natural Science Foundation of China Project (41971026), and Funded Projects of State Grid Corporation Headquarters Technology Projects, China (NYB17201800148).
Open Access This article is licensed under a Creative Commons Attribution 4.0 International License, which permits use, sharing, adaptation, distribution and reproduction in any medium or format, as long as you give appropriate credit to the original author(s) and the source, provide a link to the Creative Commons licence, and indicate if changes were made. The images or other third party material in this article are included in the article's Creative Commons licence, unless indicated otherwise in a credit line to the material. If material is not included in the article's Creative Commons licence and your intended use is not permitted by statutory regulation or exceeds the permitted use, you will need to obtain permission directly from the copyright holder. To view a copy of this licence, visit http://creativecommons.org/licenses/by/4.0/.

\section{References}

Ai H, Zhang YC, Lu W (2009) Characteristics of the interannual variations of summer precipitation days with different class intervals over eastern China. Sci Meteorol Sin 29(3):299-306

Bai AJ, Liu XD (2010) Characteristics of rainfall variation over East China during the last 50 years and their relationships with droughts and floods. J Trop Meteorol 26(2):194-200

Bai JY, Guan ZY, Bai JY et al (2014) Climatic characteristics of graded summer precipitation over East China Scientia Meteor. Sinica 34(4): 365-372

Chen CN, Zhu LQ, Tian L, Li XG (2019) Spatial-temporal changes in vegetation characteristics and climate in the Qinling-Daba Mountains. Acta Ecol Sin 39(9):1-10

Dai A, Lin X, Hsu K (2007) The frequency, intensity, and diurnal cycle of precipitation in surface and satellite observations over low- and midlatitudes. Clim Dynam 29(7 8):727-744

Duan GL, Tao JL (2004) Comparative analysis of three rainstorms in Shaanxi Province from 2000 to 2003. J Catastrophol 19(S):24-28 (in Chinese)

Fu JL, Lin X, Qian WH (2008) The temporal and spatial characteristics of graded summer rain days over China. J Trop Meteorol 25:267-278

Gao X, Bai HY, Zhang SH, He YN (2012) Climatic change tendency in Qinling Mountains from 1959 to 2009. Bull Soil Water Conserv 32(1):207-211 (in Chinese)

Jiang C, Wang F, Mu XM, Li R (2012) Effects of climate change on net primary productivity of vegetation in the northern and southern regions of the Qinling Mountains (I): temporal and spatial characteristics of climate change in recent 52a. Sci Soil Water Conserv 10(5): 56-63 (in Chinese)

Kang MY, Zhu Y (2006) Discussion and analysis on the geo-ecological boundary in Qinling Range. Acta Ecol Sin 27(7):2774-2784

Li SS, Yang SN, Liu XF (2015) Spatiotemporal variability of extreme precipitation in north and south of the Qinling-Huaihe region and influencing factors during 1960-2013. Prog Geogr 34(3):354-363 (in Chinese)

Liu YG, Ge YG, Zhou Q (2008) Precipitation changes and calamity effects at the southern regions of the Qinling Mountains. Arid Land Geogr 31(1):50-55 (in Chinese)

Ning L, Qian YF (2008) Analyses on trends of annual and seasonal four kinds of daily precipitation in China. Plateau Meteorol 27(5):1010 1020 (in Chinese)

Wang XL, Ren Y (2012) Alysis of precipitation differences and their local causes in the last 50 years around the Qinling Mountains. Clim Environ Res 17(6):911-918 (in Chinese)

Wang WY, Wang L, Li GP et al (2016) Temporal and spatial characteristics of extreme precipitation in flood season in Shaanxi Province during 1961-2013. Arid Meteorol 34(6):952-957 (in Chinese) 
Wu HW, Huang AN, Jiang YM (2013) Temporal and spatial distribution of different grades of precipitation days in East China. Clim Environ Res 18(3):387-396

Xie ZQ, Du Y, Zeng Y, Miao Q (2018) Classification of yearly extreme precipitation events and associated flood risk in the Yangtze-Huaihe River Valley. Earth Sci: J China 48(9):1153-1168 (in Chinese)

Yang B, Zhang B, An ML, Zhang TF (2014) Spatiotemporal characteristics of precipitation extremes in the Qinba Mountains Region during 1961-2011. Soil Water Conserv 21(1):110-116 (in Chinese)

Y in H, Sun Y (2007) Characteristics of extreme temperature and precipitation in China in 2017 based on ETCCDI indices. https://doi.org/ 10.12006/j.issn.1673-1719.2018.164

Yin H, Guo PW, Liu HB et al (2007) Preliminary analysis of drought/ flood events in early-summer over the central Shaanxi Plain during the past 500 years. J Nanjing Instit Meteorol 30(1):51-56 (in Chinese)

Zhai P, Zhang X, Wan H, Pan X (2005) Trends in total precipitation and frequency of daily precipitation extremes over China. J Clim 18(18): 1096-1108

Zhang LJ, Qian YF (2004) A study on the feature of precipitation concentration and its relation to flood-producing in the Yangtze River Valley of China. Chin J Geophys 47(4):622-630

Zhang TY, Sun ZB, Ni DH et al (2007) Regional characteristics of summer precipitation over the mid-lower reaches of Yangtze River during last 45 years. Trans Atmos Sci 30(4):530-537

Zhu M, Xiao TG, Yu X, Xu XH (2014) Spatial and temporal distribution characteristics of summer precipitation in Qinling and Daba Valley. Meteorol Sci Technol 42(4):663-670 